\title{
Let's get a stronger evidence base for our decisions
}

\author{
I. Diane Cooper, AHIP \\ DOI: http://dx.doi.org/10.3163/1536-5050.104.4.001
}

Some librarians think we put too much emphasis on evidence-based librarianship (E-BL). Others believe we have not done enough. Jonathan Eldredge, AHIP, believes there is plenty of research-based evidence; we are just not using it. He believes our lack of E-BL may have an impact on the health of all Americans, and I do not disagree (see his commentary in this issue).

\section{WHAT IS "EVIDENCE-BASED LIBRARIANSHIP” (E-BL)?}

Evading formal definitions, we can say E-BL is librarianship in which management and service decisions are constructed from research-based, strong evidence. Research that produces strong evidence is research that follows an accepted methodology with data obtained in a way that eliminates or mitigates biases.

The level of evidence can be graded. When making decisions, we have less confidence with low-level evidence. High levels of evidence usually come from certain types of quantitative research.

Librarianship emerged from social sciences. Traditionally, we have relied more on qualitative than quantitative research [1]. For some sciences, it is very difficult to perform quantitative research, and they must rely on other approaches. But in any science in which evidence-producing research can be done, that is usually the goal. Making decisions based on evidence has face-validity (its validity is readily apparent), and disciplines that do not want to rely on evidence-based research at all, such as those that are faith-based, can be labelled "not science."

Many of us went to library science schools and easily acknowledge the benefits of E-BL.

\section{POTENTIAL BENEFITS FROM E-BL}

- Management benefits: Purchasing resources that are more likely to be used, improved work efficiency of staff, and less wasted material.

- Higher-quality service: Less wasted time. Knowing what can be useful and anticipating demand can lead to a wider scope of services as new procedures that become validated.

- Professional confidence: Evidence-based information is more persuasive; it presents stronger arguments than inconclusive, non-generalizable, lightly supported assertions. Reading and thinking about stronger arguments should keep up librarians' professional interest and curiosity, leading to more confidence and satisfaction.

- Respect from our colleagues: Good research leads to acceptance from our scientist peers that we really do base our plans and services on a rational platform.

- More rational forecasting: And worth it for this reason, if nothing else: it improves predictability and provides some order to our lives so that we will not be as much on the edge of daily chaos.

\section{WHO WOULD ARGUE WITH E-BL?}

I think no one. Most of us endorse the goal of E-BL. The most common hyphenated word in our journal from 1966 to 2010 was evidence-based. In his fifty-year review of our publication, Mark E. Funk, AHIP, FMLA, found that "We [increasingly] prefer information to be evidence-based" [2]. Eldredge recounts the history of MLA's endorsement of evidence-based librarianship in his commentary in this issue. Nobody speaks against E-BL. 
I. Data sharing and data banks

II. Access to a randomized population

III. Multi-institute interlibrary research cooperative agreements

Table 1

Ways to strengthen our research structure

\section{SO WHAT IS THE FUSS?}

\section{First theme}

We believe there is not much research-based evidence out there, at least not much that is useful for our daily work. Some of us are content with little evidence. Others want more. So, first, how committed are we to producing high-level research evidence?

One survey respondent told me she "would rather see (non-generalizable) information for her decisions than no information." She says, "Some knowledge is better than no knowledge." But low-evidence-level research is not really useful knowledge. It can be interesting and provocative, just as case studies can. They can lead to stronger future studies and progress. We publish them in great numbers.

But their level of evidence is weak or absent. Data from low-evidence, non-generalizable studies are not better for decision making than flipping a coin and, in fact, may harbor biases that make it misleading. Decision making based on weak or absent data is not E-BL. And our survey respondent is fine with that.

Low-level research findings should not be our goal. We accept them when more definitive studies are not available, but no one should be content that we are sufficient in our research machinery when we produce mostly low-level evidence. We should be committed to ever improving our research.

\section{Second theme}

Why aren't our researchers producing more high-level useful evidence for us?

Another survey respondent said, "It is impossible for librarians to do good research." It certainly is harder to do strong-evidence-producing research than convenient research, but not impossible. So why don't we do more useful evidence-based research?

No definitive study has been done to explain why not. One study suggests researchers are impeded by lack of time and lack of money [3,4]. But that is only part of it. Maybe the barriers are more an issue of not having an adequate research structure. If we had a stronger research structure available, then strongerevidence research would be quicker and cheaper, hence more do-able. The traditional research barriers might melt away.

\section{THE WAY TO A STRONGER LIBRARY SCIENCE RESEARCH STRUCTURE}

Three straightforward elements would increase our production of useful, high-level evidence (Table 1).

1. Data sharing and data banks: Researchers collect data. Do they own the data? Perhaps, but if they share their data, others could analyze it differently and produce different insights. Others could add data together from different studies, producing stronger results. "Data sharing is essential for expedited translation of research results into knowledge, products and procedures to improve human health," the National Institutes of Health (NIH) points out. All NIH grant recipients are expected to share their data [5]. This includes grants from the National Library of Medicine (NLM) as well, even if NLM sponsorship is only partial [6]. The process can be simple. The researcher removes all data that could identify an individual, provides details of how the data were obtained, and makes the data publicly available. All library science researchers should be 
willing to share their data. The Medical Library Association (MLA) or some forward-thinking university could expedite this element.

2. Access to a randomized population: Much of our research is based on surveys. Researchers want to survey a random population, but it is extremely difficult to do. There is a solution. A trusted intermediary, such as MLA, could send a research questionnaire to a random list of its members and provide the de-identified results back to the researcher. There would be some MLA staff time required (not much), and MLA could charge a small fee for the data. To prevent being overwhelmed, MLA could have a committee evaluate the technical and policy importance of research applications and limit the service to three a year. This would lead to at least three high-level evidence projects a year, which is more than we have now.

3. Multi-institute research cooperative agreements: Multi-institute research has been found to be more reproducible and higher quality. A campaign could encourage cooperative agreements among libraries, and experts, perhaps from other disciplines, could describe models. Recently, MLA's Research Imperative Task Force has successfully encouraged MLA to allow multi-institute grant applications [7].

\section{WHAT SHOULD YOU AND I DO?}

All of us should be pushing for more useful evidence-producing research. We should not be complacent with the status quo. We need to encourage funding agencies and library stakeholders to build a greater, stronger health sciences library research structure. We need to point to ideas like those described here.

\section{REFERENCES}

1. Crumley E, Koufogiannakis D. Developing evidence-based librarianship: practical steps for implementation. Health Inf Libr J. 2002 Jun;19(2):61-70.

2. Funk ME. Our words, our story: a textual analysis of articles published in the Bulletin of the Medical Library Association/Journal of the Medical Library Association from 1961 to 2010. J Med Libr Assoc. 2013 Jan;101(1):12-20. DOI: http://dx.doi.org/10.3163/1536-5050.101.1.003.

3. Cooper ID. Research survey suggests opportunities. J Med Libr Assoc. 2016 Apr;104(2):165. DOI: http://dx.doi.org/ 10.3163/1536-5050.104.2.014.

4. Lessick S, Perryman C, Billman BL, Alpi KM, De Groote SL, Babin Jr. TD. Research engagement of health sciences librarians: a survey of research-related activities and attitudes. J Med Libr Assoc. 2016 Apr;104(2):166-73. DOI: http:// dx.doi.org/10.3163/1536-5050.104.2.015.

5. National Institutes of Health. NIH data sharing policy [Internet]. The Institutes [cited 27 Jun 2016]. <http://grants. nih.gov/grants/policy/data_sharing/>.

6. Cravedi K (National Library of Medicine). Personal communication. 6 Jun 2016.

7. Lessick S. Personal communication. 16 May 2016.

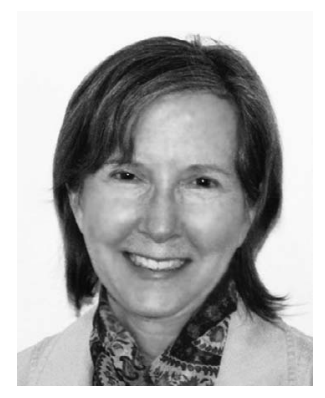

\section{AUTHOR'S AFFILIATION}

I. Diane Cooper, AHIP, jmlaeditorbox@gmail.com, Editor-in-Chief, Journal of the Medical Library Association 